\title{
Antioxidant Effects of Eugenol on Oxidative Stress Induced by Hydrogen Peroxide in Islets of Langerhans Isolated from Male Mouse
}

\author{
Ali Akbar Oroojan $\mathbb{D}^{1},{ }^{1}$ Narges Chenani $\mathbb{D}^{2},{ }^{2}$ and Marzieh An'aam $\mathbb{D}^{3}$ \\ ${ }^{1}$ Department of Physiology, Faculty of Medicine, Student Research Committee, Dezful University of Medical Sciences, Dezful, Iran \\ ${ }^{2}$ Student Research Committee, Faculty School of Paramedical Sciences, Dezful University of Medical Sciences, Dezful, Iran \\ ${ }^{3}$ Faculty of Medicine, Dezful University of Medical Sciences, Dezful, Iran
}

Correspondence should be addressed to Ali Akbar Oroojan; aliakbar_oroojan@yahoo.com

Received 12 July 2020; Revised 14 December 2020; Accepted 17 December 2020; Published 30 December 2020

Academic Editor: Dirk Uhlmann

Copyright (c) 2020 Ali Akbar Oroojan et al. This is an open access article distributed under the Creative Commons Attribution License, which permits unrestricted use, distribution, and reproduction in any medium, provided the original work is properly cited.

\begin{abstract}
Background. The antioxidant system in islets of Langerhans is weak, which can lead to diabetes. Meanwhile, the main component of cloves that produce antioxidant effects is eugenol. Accordingly, the present study was conducted to investigate the antioxidant effect of eugenol on oxidative stress induced by hydrogen peroxide $\left(\mathrm{H}_{2} \mathrm{O}_{2}\right)$ in islets of Langerhans isolated from the male mice. Materials and Methods. In this experimental study, adult Naval Medical Research Institute (NMRI) mice (20-25g) were prepared. The collagenase digestion method was used for dissecting the islets of Langerhans. $\mathrm{H}_{2} \mathrm{O}_{2} 50 \mu \mathrm{M}$ was administered for 30 min to induce oxidative stress, with 50,100 , and $200 \mu \mathrm{M}$ of eugenol employed for 2 hours before the administration of $\mathrm{H}_{2} \mathrm{O}_{2}$. The experimental groups were divided into five groups: (control, $\mathrm{H}_{2} \mathrm{O}_{2}$, and $\mathrm{H}_{2} \mathrm{O}_{2}$ +eugenol 50, 100, and $200 \mu \mathrm{M}$ ). Finally, the islet's lipid peroxidation and antioxidants levels were measured by the ELISA assay method. Results. Malondialdehyde (MDA), total antioxidant capacity (TAC), superoxide dismutase (SOD), and catalase (CAT) increased in all groups when compared to the control $(P<0.05)$. MDA diminished in $\mathrm{H}_{2} \mathrm{O}_{2}$ +eugenol 50, 100, and $200 \mu \mathrm{M}(P<0.01)$ groups versus the $\mathrm{H}_{2} \mathrm{O}_{2}$. TAC was elevated when eugenol 50,100, and $200 \mu \mathrm{M}$ was administered in oxidative stress-induced islets $(P<0.001)$. Also, CAT increased in the $\mathrm{H}_{2} \mathrm{O}_{2}$ +eugenol $50(P<0.05)$ group in comparison with the $\mathrm{H}_{2} \mathrm{O}_{2}$ group. Conclusions. In conclusion, $\mathrm{H}_{2} \mathrm{O}_{2}$ induced oxidative stress and lipid peroxidation in the islets, and administration of eugenol recovered these alterations by raising the level of TAC and CAT, while reducing MDA as a lipid peroxidation biomarker.
\end{abstract}

\section{Introduction}

Increased blood glucose triggers the onset of a series of cascading reactions, which eventually lead to increased production of free radicals and oxidative stress in various tissues such as the pancreas [1]. Numerous reports have shown that reactive oxygen species (ROS) can induce damage in cells and tissues [2]. Several endogenous antioxidant compounds including superoxide dismutase (SOD), glutathione, and catalase (CAT) protect cells against free radicals, especially ROS. Meanwhile, studies have shown a significant reduction in the amount of enzymatic and nonenzymatic antioxidants in the blood and cells during chronic diseases such as diabetes [3].
Oxidative stress refers to an imbalance between the production of oxygen free radicals and the body's antioxidant defense capacity [4]. Also, free radicals reduce the body's antioxidant activity causing enzyme activity disorder as well as increased lipid peroxidation [5]. When unsaturated fatty acids are exposed to free radicals, a series of chain reactions result in the formation of electron-friendly lipids and lipid peroxidation. Malondialdehyde (MDA) is one of the most toxic types of aldehydes, causing lipid and tissue damage due to lipid peroxidation [6]. The use of antioxidant compounds will play an important role in reducing the consequences of chronic diseases such as diabetes. In this regard, the administration of plant origin compounds is associated 
with fewer side effects [7]. It has been reported that medicinal plants and active ingredients extracted from them can play a protective role against oxidative stress and tissue damage via increasing the antioxidant activity of CAT and SOD enzymes. As the weakening of the antioxidant system in the pancreas or islets of Langerhans induces the complications of diabetes, it is possible to prevent the progression of this disease by strengthening the antioxidant defense system in diabetic cases [8-10]. Clove has several traditional therapeutic properties including medicinal antiseptic, analgesic, and antimicrobial effects. The main component of cloves that produce these effects is eugenol. Eugenol (4-allyl-2-methoxy phenol) is a phenolic compound with different applications in the preparation of dental materials, health products, beverages, and baked foods. This compound can function as an antioxidant and prevent free radical-mediated diseases such as cancer, inflammation, and type 2 diabetes mellitus (T2DM), as well as cardiovascular, neurodegenerative, and periodontal disease $[11,12]$. It has also been revealed that polyphenols have neuroprotective effects in addition to the beneficial effects against cardiovascular disease, diabetes, and geriatric conditions. Administration of flavonoid compounds with vitamin $\mathrm{E}$ has shown a protective effect against Alzheimer's and Parkinson's diseases via reducing ROS overproduction [13]. Further, alpha-lipoic acid with antioxidant activities has a therapeutic effect against deltamethrininduced hepatic and renal oxidative damages through inhibiting lipid peroxidation and scavenging free radicals [14]. Pancreatic islets are more susceptible to oxidative stress and free radicals than other cells due to their low antioxidant defense capacity. Also, antioxidants such as phenolic compounds or flavonoids make pancreatic islets stronger to conflict with oxidative stress, especially during diabetes $[15,16]$. Thus, due to the antioxidant effects of eugenol and the susceptibility of the pancreatic islet to oxidative stress which can cause diabetes, the present study was conducted to examine the antioxidant effect of eugenol on oxidative stress induced by hydrogen peroxide $\left(\mathrm{H}_{2} \mathrm{O}_{2}\right)$ in islets of Langerhans isolated from the male mouse.

\section{Materials and Methods}

2.1. Animal's Preparation. In this experimental study, adult Naval Medical Research Institute (NMRI) mice (20-25g) were kept at a 12:12 hour light: dark cycle. The animals were treated in accordance with the principles and guidelines on animal care of Dezful University of Medical Sciences as reviewed by an ethics committee (IR.DUMS.REC.1398.022), as well as free access to tap water and commercial chow ad libitum.

2.2. Islet Isolation. The islets of Langerhans were isolated by the protocol for the isolation of islets from rodent pancreas using collagenase digestion. Briefly, the animals were anesthetized with ketamine/xylazine $(70 / 10 \mathrm{mg} / \mathrm{kg})$, and their pancreas removed and transferred to a Petri dish containing Krebs-bicarbonate buffer solution (Merck, Germany). Then, the separated pancreas was cut into $1 \mathrm{~mm}$ pieces and centrifuged at $100 \times \mathrm{g}$ for $5 \mathrm{~min}$. Krebs-bicarbonate buffer solution plus collagenase type $\mathrm{P}$ (1-2 mg/pancreas) (Roche, Germany) were added to the sediment of the centrifuged conical tube to separate the islets from exocrine tissue. Next, the conical tube was transferred to an incubator at $37^{\circ} \mathrm{C}$ with 800 oscillations for 5-10 min. Then, a cold Krebs-bicarbonate buffer was added to the conical tube to stop collagenase digestion and centrifuged at $500 \times \mathrm{g}$ for $5 \mathrm{~min}$. Finally, the isolated islets were transferred to a Petri dish and separated manually under a stereomicroscope [17].

2.3. Islets Induced Oxidative Stress and Treatment. To create oxidative stress in the isolated islets of Langerhans, $\mathrm{H}_{2} \mathrm{O}_{2}$ $(50 \mu \mathrm{M})$ was added to each islet's sample and incubated for $30 \mathrm{~min}$. Then, the samples were centrifuged at $400 \times \mathrm{g}$ for $10 \mathrm{~min}$. In order to reduce the oxidative stress in islets, 50 , 100 , and $200 \mu \mathrm{M}$ of eugenol were added to each islet's sample and incubated for 2 hours at $37^{\circ} \mathrm{C}$; after the incubation period, the oxidative-induced protocol with $\mathrm{H}_{2} \mathrm{O}_{2}(50 \mu \mathrm{M})$ was repeated. Finally, the supernatant of each microtube was stored at $-70^{\circ} \mathrm{C}$ until the experimental measurement. Each microtube contained 7 islets, and the number of samples is repeated 6 times for each group $[18,19]$.

\subsection{Grouping. Group 1: control}

Group 2: $\mathrm{H}_{2} \mathrm{O}_{2}$ (it received $50 \mu \mathrm{M}$ of $\mathrm{H}_{2} \mathrm{O}_{2}$ for $30 \mathrm{~min}$ )

Group 3: $\mathrm{H}_{2} \mathrm{O}_{2}+$ eugenol $(50 \mu \mathrm{M})$ (it received $50 \mu \mathrm{M}$ of eugenol for 2 hours after which $\mathrm{H}_{2} \mathrm{O}_{2}(50 \mu \mathrm{M})$ was added to each sample for $30 \mathrm{~min}$ )

Group 4: $\mathrm{H}_{2} \mathrm{O}_{2}$ +eugenol $(100 \mu \mathrm{M})$ (it received $100 \mu \mathrm{M}$ of eugenol for 2 hours after which $\mathrm{H}_{2} \mathrm{O}_{2}(50 \mu \mathrm{M})$ was added to each sample for $30 \mathrm{~min}$ )

Group 5: $\mathrm{H}_{2} \mathrm{O}_{2}+$ eugenol $(200 \mu \mathrm{M})$ (it received $200 \mu \mathrm{M}$ of eugenol for 2 hours after which $\mathrm{H}_{2} \mathrm{O}_{2}(50 \mu \mathrm{M})$ was added to each sample for $30 \mathrm{~min}$ )

2.5. Lipid Peroxidation and Antioxidant Measurements. To measure the level of MDA, total antioxidant capacity (TAC), SOD, and CAT in the isolated islets of Langerhans, the ELISA method as well as specific commercial kits (Teb Pazhouhan Razi, Iran) was used.

2.6. Statistical Analysis. The results were statistically analyzed using the Statistical Package for Social Sciences (SPSS) software with one-way analysis of variance (ANOVA), followed by post hoc least significant difference (LSD) tests. All results were represented as mean \pm standard error (SE) where $P$ was considered significant at less than 0.05 in all experiments.

\section{Results}

3.1. The Role of Eugenol in Islet's Lipid Peroxidation. The results of this study showed that MDA increased in all groups when compared to the control $(P<0.001)$. This lipid peroxidation variable diminished in $\mathrm{H}_{2} \mathrm{O}_{2}$ plus eugenol 50 $(P<0.001), \quad 100$, and $200 \mu \mathrm{M}(P<0.01)$ administrated groups versus the $\mathrm{H}_{2} \mathrm{O}_{2}$ group (Figure 1).

3.2. Antioxidant Activity of Eugenol in Isolated Islets of Langerhans. The islets' level of TAC increased in $\mathrm{H}_{2} \mathrm{O}_{2}$ 


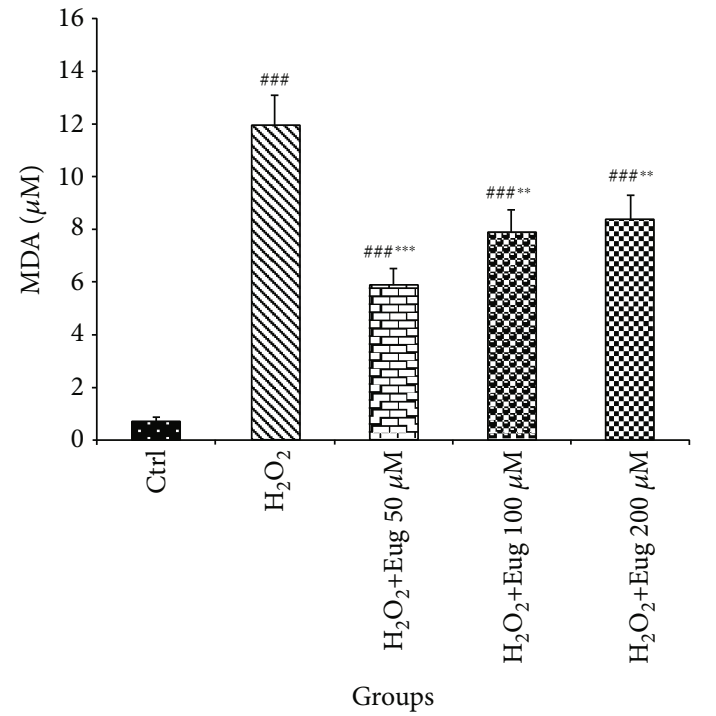

Figure 1: Effects of $\mathrm{H}_{2} \mathrm{O}_{2}$ and eugenol on the MDA level of islets of Langerhans. Data are expressed as the mean \pm SE, $n=6$ (7 islets in each sample). ${ }^{\# \#} P<0.001$ significantly different with the control group; ${ }^{* *} P<0.01$ and ${ }^{* * *} P<0.001$ significantly different with the $\mathrm{H}_{2} \mathrm{O}_{2}$ group. Eug: eugenol.

$(P<0.05)$, as well as $\mathrm{H}_{2} \mathrm{O}_{2}$ plus eugenol 50,100 , and $200 \mu \mathrm{M}$ $(P<0.001)$ groups compared with the control. This variable revealed a significant increase following eugenol 50, 100, and $200 \mu \mathrm{M}(P<0.001)$ administration under oxidative stress islets compared to the $\mathrm{H}_{2} \mathrm{O}_{2}$ group (Figure 2).

The results indicated that the SOD level rose in all groups when compared to control $(P<0.01)$. However, this antioxidant enzyme did not show any significant alteration across the $\mathrm{H}_{2} \mathrm{O}_{2}$-administered groups (Figure 3).

CAT level increases in $\mathrm{H}_{2} \mathrm{O}_{2}(P<0.01)$ and $\mathrm{H}_{2} \mathrm{O}_{2}$ plus eugenol $50(P<0.001), 100$, and $200 \mu \mathrm{M}(P<0.01)$ groups compared to the control. Also, this enzyme was elevated in the $\mathrm{H}_{2} \mathrm{O}_{2}$ plus eugenol $50 \mu \mathrm{M}(P<0.05)$ group in comparison with the $\mathrm{H}_{2} \mathrm{O}_{2}$ group (Figure 4).

\section{Discussion}

The results of the present study showed that the induction of oxidative stress by $\mathrm{H}_{2} \mathrm{O}_{2}$ would lead to higher MDA levels in the isolated islets of Langerhans. However, $\mathrm{H}_{2} \mathrm{O}_{2}$ could increase TAC, SOD, and CAT, but this increasing effect could not improve the damage induced by oxidative stress and lipid peroxidation in the islets. The administration of eugenol decreased MDA along with increase TAC and CAT in pancreatic islets under oxidative stress condition induced by $\mathrm{H}_{2} \mathrm{O}_{2}$. Also, the effect of low doses of eugenol on improving the damage induced by oxidative stress was greater than that of other doses. This effect can be attributed to the fact that a low dose of eugenol resulted in a significant increase in catalase as well as in further reduction in MDA in the isolated islets.

Pancreatic $\beta$ cells are sensitive to oxidative stress where ROS may play a central role in $\beta$ cell death causing T1DM. Also, this disorder has a secondary pathogenic role in the

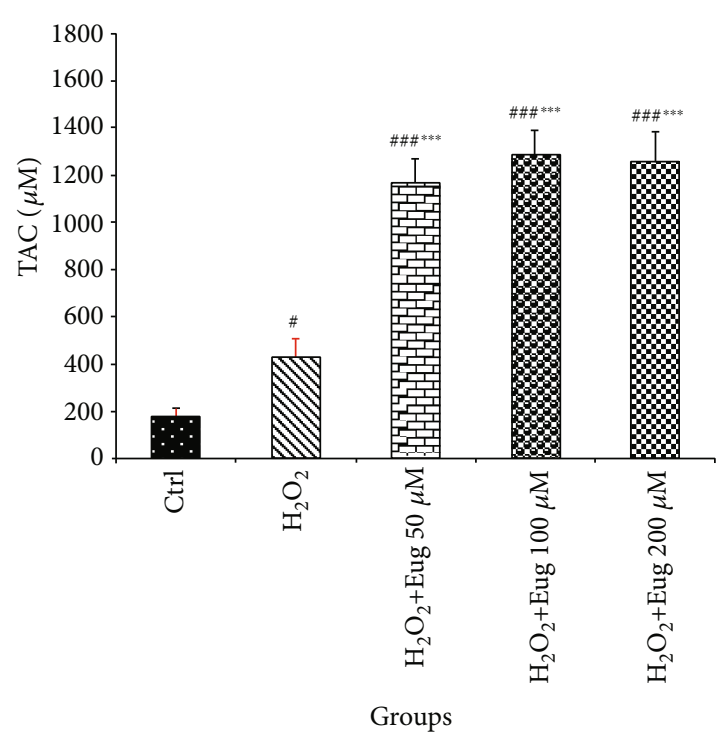

Figure 2: Effects of $\mathrm{H}_{2} \mathrm{O}_{2}$ and eugenol on the TAC level of islets of Langerhans. Data are expressed as the mean \pm SE, $n=6$ (7 islets in each sample). ${ }^{\#} P<0.05$ and ${ }^{\# \#} P<0.001$ significantly different with the control group; ${ }^{* *} P<0.001$ significantly different with the $\mathrm{H}_{2} \mathrm{O}_{2}$ group. Eug: eugenol.

development of T2DM. On the other hand, it was demonstrated that antioxidants such as phenolic compounds reduced this complication. $\mathrm{H}_{2} \mathrm{O}_{2}$ has multiple effects on $\beta$ cells including metabolic inhibition and enhancing plasma membrane permeability, impairing glucose metabolism, and reducing insulin secretion [20]. Oxidative stress can increase the production of hydrogen peroxide and ketoaldehydes through spontaneous glucose oxidation in pancreatic $\beta$ cell, causing type 1 and type 2 diabetes [21]. In addition, several phenolic compounds such as quercetin, catechin, and ascorbic acid could improve the antioxidant defense in various cells. Further, these flavonoids recovered $\mathrm{H}_{2} \mathrm{O}_{2}$ induced proliferation inhibition in $\beta$ cell, and it was suggested that these antioxidants can be used in T2DM to increase $\beta$ cell proliferation [22]. Diabetes mellitus disrupts the oxidant/antioxidant balance in healthy tissues such as the heart. This chronic disease increases the main cardiac variables including plasma troponin I and creatine kinase-MB (CK-MB) via reducing the antioxidant enzyme level causing cardiac damages. Also, it was demonstrated that thymoquinone as a potent antioxidant phytochemical ameliorates the cardiac injuries in diabetic rats via reducing oxidative stress and can also increase cell survival [23]. Overproduction of ROS is a common pathway of diverse pathogenic mechanisms of diabetic complications. Bioflavonoids as antioxidants are therapeutic options against diabetes mellitus and its related complications. Thus, maintaining glycemic control, blocking the pathways of free radical production, and increasing the antioxidants enzyme level can be a promising approach to the treatment of hyperglycemiainduced diabetes complications in humans [24]. Accordingly, present results suggested that eugenol may play a critical role in the treatment of DM through its antioxidant properties and reducing lipid peroxidation in pancreatic 


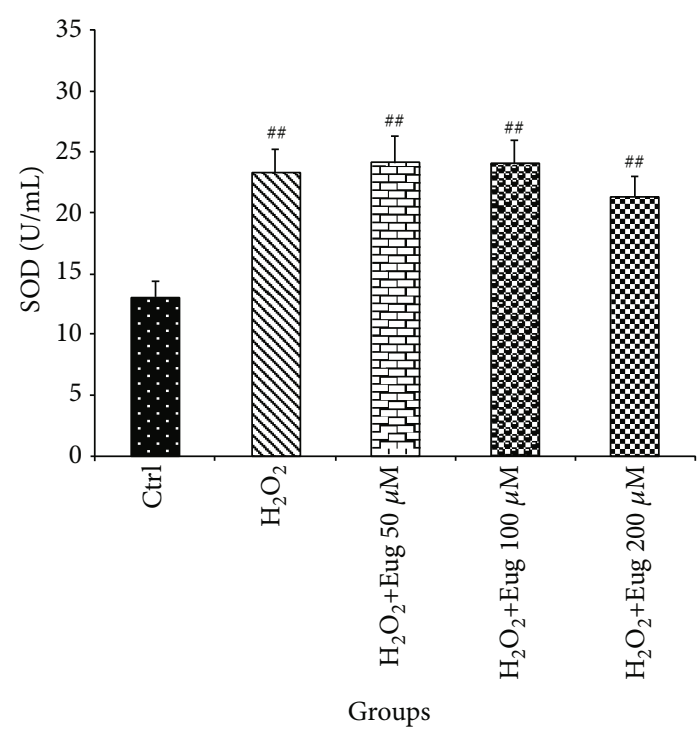

FIgURE 3: Effects of $\mathrm{H}_{2} \mathrm{O}_{2}$ and eugenol on the SOD level of islets of Langerhans. Data are expressed as the mean \pm SE, $n=6$ (7 islets in each sample). ${ }^{\# \#} P<0.01$ significantly different with the control group. Eug: eugenol.

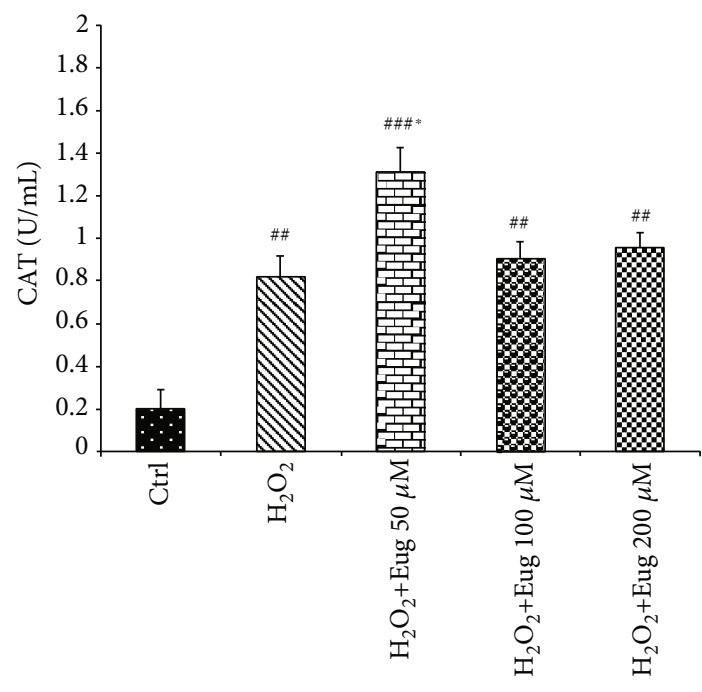

Groups

FIGURE 4: Effects of $\mathrm{H}_{2} \mathrm{O}_{2}$ and eugenol on the CAT level of islets of Langerhans. Data are expressed as the mean \pm SE, $n=6$ ( 7 islets in each sample). ${ }^{\# \#} P<0.01$ and ${ }^{\# \# \#} P<0.001$ significantly different with the control group; ${ }^{*} P<0.05$ significantly different with the $\mathrm{H}_{2} \mathrm{O}_{2}$ group. Eug: eugenol.

islets. Nevertheless, future clinical studies are required to demonstrate this recommendation.

It was revealed that antioxidant agents such as polyphenols or flavonoids scavenge free radicals depending on their concentration [11]. Further, these compounds can promote the generation of free radicals such as $\mathrm{H}_{2} \mathrm{O}_{2}$ at higher concentrations [20]. So, in accordance with a previous study, the reason for the greater effect of eugenol on low doses is the influence of this dose on reducing oxidative stress and improving the performance of antioxidant defenses in isolated pancreatic islets.

\section{Conclusion}

In conclusion, $\mathrm{H}_{2} \mathrm{O}_{2}$ induced oxidative stress and lipid peroxidation in the isolated islet of Langerhans, and administration of eugenol recovered these alterations by raising the level of TAC and CAT and reducing MDA as a lipid peroxidation biomarker. Also, among the administered concentrations of eugenol, a low dose of this phenolic compound was more potent to produce a therapeutic effect in the function of antioxidant enzymes and reducing the oxidative stress of the pancreatic islet. Hence, this dose of eugenol could be used to treat diabetes by improving the function of $\beta$ cells in the islets of Langerhans, but a future clinical study is required to clarify this finding.

\section{Data Availability}

The data are available from the corresponding author upon request.

\section{Conflicts of Interest}

The authors declare no conflict of interest regarding the publication of this manuscript.

\section{Acknowledgments}

This study is a research project that was labeled (IR.DUMS.REC.1398.022), and financial support was provided by the Vice-Chancellor of Research, Dezful University of Medical Sciences, Dezful, Iran.

\section{References}

[1] G. Davì, A. Falco, and C. Patrono, "Lipid peroxidation in diabetes mellitus," Antioxidants \& Redox Signaling, vol. 7, no. 1-2, pp. 256-268, 2005.

[2] Z. Fatehi-Hassanabad, C. B. Chan, and B. L. Furman, "Reactive oxygen species and endothelial function in diabetes," European Journal of Pharmacology, vol. 636, no. 1-3, pp. 8-17, 2010.

[3] B. Shrilatha and Muralidhara, "Occurrence of oxidative impairments, response of antioxidant defences and associated biochemical perturbations in male reproductive milieu in the streptozotocin-diabetic rat," International Journal of Andrology, vol. 30, no. 6, pp. 508-518, 2007.

[4] S. Moussa, "Oxidative stress in diabetes mellitus," Romanian Journal of Biophysics, vol. 18, no. 3, pp. 225-236, 2008.

[5] L. Rochette, M. Zeller, Y. Cottin, and C. Vergely, "Diabetes, oxidative stress and therapeutic strategies," Biochimica et Biophysica Acta (BBA)-General Subjects, vol. 1840, no. 9, pp. 2709-2729, 2014.

[6] S. Sabouri, J. Mohtadinia, A. Aliasgarzadeh, G. S. Noumi, and E. Yousefirad, "The relationship between serum level of chromium and serum malondialdehyde in patients with type II diabetes," Shahrekord University of Medical Sciences Journal, vol. 12, no. 2, pp. 1-6, 2010. 
[7] J. Harasym and R. Oledzki, "Effect of fruit and vegetable antioxidants on total antioxidant capacity of blood plasma," Nutrition, vol. 30, no. 5, pp. 511-517, 2014.

[8] V. Demidchik, "Mechanisms of oxidative stress in plants: from classical chemistry to cell biology," Environmental and Experimental Botany, vol. 109, pp. 212-228, 2015.

[9] M. Valko, C. Rhodes, J. Moncol, M. Izakovic, and M. Mazur, "Free radicals, metals and antioxidants in oxidative stressinduced cancer," Chemico-Biological Interactions, vol. 160, no. 1, pp. 1-40, 2006.

[10] R. Rahbarian, H. Sepehri-Moghadam, and S. D. Sadoughi, "The effects of aqueous extract of launaea acanthodes on oxidative stress parameters of red blood cells in diabetic rats," Journal of Rafsanjan University of Medical Sciences, vol. 14, no. 10, pp. 865-878, 2016.

[11] S. Fujisawa and Y. Murakami, "Eugenol and its role in chronic diseases," in Drug Discovery from Mother Nature, S. Gupta, S. Prasad, and B. Aggarwal, Eds., vol. 929 of Advances in Experimental Medicine and Biology, pp. 45-66, Springer, Cham, 2016.

[12] J. N. Barboza, C. da Silva Maia Bezerra Filho, R. O. Silva, J. V. R. Medeiros, and D. P. de Sousa, "An overview on the antiinflammatory potential and antioxidant profile of eugenol," Oxidative Medicine and Cellular Longevity, vol. 2018, Article ID 3957262, 9 pages, 2018.

[13] A. W. K. Yeung, N. T. Tzvetkov, O. S. El-Tawil, S. G. Bungău, M. M. Abdel-Daim, and A. G. Atanasov, "Antioxidants: scientific literature landscape analysis," Oxidative Medicine and Cellular Longevity, vol. 2019, Article ID 8278454, 11 pages, 2019.

[14] R. H. Abdou and M. M. Abdel-Daim, "Alpha-lipoic acid improves acute deltamethrin-induced toxicity in rats," Canadian Journal of Physiology and Pharmacology, vol. 92, no. 9, pp. 773-779, 2014.

[15] M. Rahimifard, M. Navaei-Nigjeh, N. Mahroui et al., "Improvement in the function of isolated rat pancreatic islets through reduction of oxidative stress using traditional Iranian medicine," Cell Journal, vol. 16, no. 2, pp. 147-163, 2014.

[16] K. Mnafgui, F. Kaanich, A. Derbali et al., "Inhibition of key enzymes related to diabetes and hypertension by eugenol in vitro and in alloxan-induced diabetic rats," Archives of Physiology and Biochemistry, vol. 119, no. 5, pp. 225-233, 2013.

[17] J. F. O’Dowd and C. J. Stocker, "Isolation and purification of rodent pancreatic islets of Langerhans," in Type 2 Diabetes, C. Stocker, Ed., vol. 2076 of Methods in Molecular Biology, pp. 179-184, Humana, New York, NY, 2020.

[18] H. K. Jo, G. W. Kim, K. J. Jeong, D. Y. Kim, and S. H. Chung, "Eugenol ameliorates hepatic steatosis and fibrosis by downregulating SREBP1 gene expression via AMPK-mTORp70S6K signaling pathway," Biological \& Pharmaceutical Bulletin, vol. 37, no. 8, pp. 1341-1351, 2014.

[19] A. Srivastava, N. M. Bhatt, T. P. Patel, N. Dadheech, A. Singh, and S. Gupta, "Anti-apoptotic and cytoprotective effect of Enicostemma littorale against oxidative stress in Islets of Langerhans," Pharmaceutical Biology, vol. 54, no. 10, pp. 2061-2072, 2016.

[20] T. Lapidot, M. D. Walker, and J. Kanner, "Antioxidant and prooxidant effects of phenolics on pancreatic $\beta$-cells in vitro," Journal of Agricultural and Food Chemistry, vol. 50, no. 25 , pp. 7220-7225, 2002.
[21] A. Ahangarpour, S. Alboghobeish, A. Oroojan, and M. Dehghani, "Mice pancreatic islets protection from oxidative stress induced by single-walled carbon nanotubes through naringin," Human \& Experimental Toxicology, vol. 37, no. 12, pp. 1268-1281, 2018.

[22] J. Wang and H. Wang, "Oxidative stress in pancreatic beta cell regeneration," Oxidative Medicine and Cellular Longevity, vol. 2017, Article ID 1930261, 9 pages, 2017.

[23] M. S. Atta, A. H. El-Far, F. A. Farrag, M. M. Abdel-Daim, S. K. Al Jaouni, and S. A. Mousa, "Thymoquinone attenuates cardiomyopathy in streptozotocin-treated diabetic rats," Oxidative Medicine and Cellular Longevity, vol. 2018, Article ID 7845681, 10 pages, 2018.

[24] O. R. Ayepola, N. L. Brooks, and O. O. Oguntibeju, "Oxidative stress and diabetic complications: the role of antioxidant vitamins and flavonoids," in Antioxidant-Antidiabetic Agents and Human Health, pp. 923-931, Oluwafemi Oguntibeju, IntechOpen, 2014. 